\title{
Pemodelan Angka Buta Huruf di Kabupaten/Kota se-Jawa Timur dengan Metode Geographically Weighted t Regression
}

\author{
Nindya Kemala Astuti, Purhadi, dan Shofi Andari \\ Departemen Statistika, Fakultas MIPA, Institut Teknologi Sepuluh Nopember (ITS) \\ e-mail: shofi.andari@statistika.its.ac.id
}

\begin{abstract}
Abstrak-Pendidikan merupakan suatu elemen yang sangat penting dalam perkembangan suatu bangsa. Beberapa upaya yang dilakukan pemerintah dalam hal pendidikan dimaksudkan agar dapat memberantas buta huruf atau buta aksara. Indikator yang digunakan untuk mengukur tingkat buta huruf adalah Angka Buta Huruf. Namun rata-rata angka buta huruf di Indonesia masih tergolong tinggi (4,27\%). Pengukuran angka buta huruf merupakan nilai yang kontinu dan berdistribusi t. Penelitian ini menggunakan metode regresi $t$ untuk menyesuaikan distribusi variabel responnya. Mempertimbangkan adanya aspek spasial yang muncul pada data, perlu dilakukan modifikasi pada pemodelan regrei $t$, yaitu dengan menerapkan pembobot spasial. Oleh karena itu, metode regresi yang diusulkan dalam penelitian ini yaitu model regresi terboboti atau GWtR. Variabel yang signifikan pada pemodelan regresi $t$ merupakan angka partisipasi murni tingkat SD, rasio murid-guru, tingkat pengangguran terbuka, persentase penduduk miskin dan persentase balita gizi buruk. Sedangkan variabel yang signifikan pada pemodelan GWtR adalah angka partisipasi murni tingkat SD, rasio murid-guru, tingkat pengangguran terbuka dan persentase penduduk miskin. Perbandingan kebaikan kedua model menunjukkan bahwa metode terbaik untuk memodelkan angka buta huruf di kabupaten/kota se-Jawa Timur adalah GWtR.
\end{abstract}

Kata Kunci-Angka Buta Huruf, Regresi t, GWtR.

\section{PENDAHULUAN}

$\mathrm{P}$ ENDIDIKAN merupakan suatu elemen yang sangat penting dalam perkembangan suatu bangsa. Dengan pendidikan, anak-anak diasah melalui pengetahuan yang positif dalam menemukan dan merumuskan tujuan untuk dirinya di masa-masa mendatang sesuai dengan tujuan pendidikan nasional yang ditetapkan undang-undang nomor 20 tahun 2003 tentang Sistem Pendidikan Nasional. Dalam undang-undang tersebut ditegaskan bahwa pendidikan nasional bertujuan mencerdaskan kehidupan bangsa dan meningkatkan manusia Indonesia seutuhnya yaitu manusia yang beriman dan bertakwa terhadap Tuhan Yang Maha Esa, berbudi pekerti luhur [1].

Beberapa upaya yang dilakukan pemerintah provinsi Jawa Timur dalam hal pendidikan antara lain bantuan biaya pendidikan, dana BOS, beasiswa, program peningkatan tenaga pendidik, penyediaan sarana prasarana penunjang pendidikan dan lain sebagainya. Hal tersebut dimaksudkan agar dapat memberantas buta huruf atau buta aksara dan juga agar masyarakat dapat memperoleh pendidikan secara menyeluruh dan merata. Indikator yang digunakan untuk mengukur tingkat buta huruf adalah Angka Buta Huruf. Namun rata-rata angka buta huruf di Indonesia adalah $4,27 \%$, masih belum mendekati $0 \%$ [2].

Jawa Timur merupakan provinsi yang dikenal memiliki perekonomian yang tinggi tetapi dalam hal pendidikan masih dikatakan rendah, termasuk masih tingginya angka buta huruf. Menurut data Badan Pusat Statistik Jawa Timur tercatat angka buta huruf untuk provinsi Jawa Timur sebesar $7,71 \%$. Dengan tingginya angka buta huruf di Jawa Timur, maka ingin dilakukan penelitian mengenai faktor-faktor yang mempengaruhi angka buta huruf kabupaten/kota di Jawa Timur.

Objek yang akan digunakan berupa kabupaten/kota di provinsi Jawa Timur maka unit pengamatannya akan berupa wilayah atau tempat (spatial). Jarak antara satu wilayah dengan wilayah lain juga perlu diperhatikan dalam penentuan faktor yang mempengaruhi angka buta huruf. Salah satu metode statistik yang memperhitungkan aspek spasial adalah Geographically Weighted Regression (GWR). GWR sendiri adalah metode pengembangan dari model regresi dimana setiap parameter dihitung pada setiap lokasi, sehingga pada setiap titik lokasi geografis mempunyai nilai parameter regresi yang berbeda-beda [3]. Pada penelitian ini dilakukan pemodelan Angka Buta Huruf di Provinsi Jawa Timur dengan metode $G W t R$ karena variabel respon yang diteliti berbentuk kontinu dan memperhatikan aspek spasial sehingga hubungan antara variabel respon dan variabel prediktor dapat diketahui di masing-masing kabupaten/kota di Provinsi Jawa Timur. Selain itu, angka buta huruf di Provinsi Jawa Timur memiliki distribusi $t$ dengan ciri-ciri kurva yang hampir sama dengan distribusi normal standar dan karakteristik setiap kabupaten/kota di Provinsi Jawa Timur juga berbeda. Hal ini menunjukkan ada pengaruh faktor lokasi atau spasial sehingga metode $G W t R$ sangat tepat untuk digunakan.

Penelitian ini diharapkan dapat mengetahui faktor-faktor yang mempengaruhi angka buta huruf sehingga dapat dilakukan upaya pencegahan oleh pemerintah provinsi pusat.

\section{TINJAUAN PUSTAKA}

\section{A. Pengujian Distribusi}

Pengujian Kolomogorv-Smirnov merupakan salah satu metode statistik yang digunakan dalam pengujian kesesuaian distribusi. Hipotesis yang digunakan dalam pengujian Kolmogorov-Smirnov adalah sebagai berikut.

$H_{0}: F_{(y)}=F_{(y)}^{0}$ (Variabel dependen sesuai dengan

distribusi dugaan)

$H_{1}: F_{(y)} \neq F_{(y)}^{0} \quad$ (Variabel dependen tidak sesuai dengan

distribusi dugaan)

Statistik uji:

$$
D=\operatorname{Sup}\left|F_{n}(x)-F_{0}(x)\right|
$$


Tolak $H_{0}$ jika nilai $D_{\text {hit }}>D_{\alpha}$ atau p-value $<\alpha$ yang artinya distribusi variabel dependen tidak sesuai dengan distribusi dugaan.

\section{B. Multikolinearitas}

Salah satu cara untuk mendeteksi adanya kasus multikolinearitas dapat dilihat melalui nilai variance inflation factors (VIF) yang dinyatakan sebagai berikut [4].

$$
V I F_{j}=\frac{1}{1-R_{j}^{2}}
$$

\section{Regresit}

Model regresi univariat $t$ merupakan model regresi dengan variabel respon $\mathrm{Y}$ berdistribusi $t$ dan data yang diamati hanya memiliki satu variabel respon dengan variabel prediktor $X_{1}, X_{2}, \mathrm{~L}, X_{k}$. Jika hubungan linier antara variabel bebas $X_{1}, X_{2}, \mathrm{~L}, X_{k}$ dengan variabel respon $\mathrm{Y}$ untuk pengamatan ke- $i$ dinyatakan sebagai:

$$
\mathrm{y}_{i}=\beta_{0}+\sum_{p=1}^{k} \beta_{i} x_{i p}+\varepsilon_{i} ; i=1,2, . ., \mathrm{n}
$$

Selanjutnya jika $\mathrm{y}_{i}$ bersifat independen dan identik berdistribusi $t$, parameter lokasi $\underset{\% \%}{x_{\%}^{T}} \beta$, parameter skala $\psi$, dan derajat bebas $\tau$, maka fungsi densitas dari $\mathrm{y}_{i}$ adalah [5]

$$
f\left(y_{i}\right)=\frac{\Gamma\left(\frac{\tau+1}{2}\right)}{(\pi \tau)^{\frac{1}{2}} \Gamma\left(\frac{\tau}{2}\right) \psi^{\frac{1}{2}}}\left[1+\frac{\left(y_{i}-x_{\%}^{\tau} \beta\right)^{2}}{\tau \psi}\right]^{-\frac{\tau+1}{2}} ;-\infty<y_{i}<\infty
$$

\section{Uji Aspek Spasial}

Dependensi spasial merupakan indikasi pada pengamatan di suatu lokasi berpengaruh terhadap pengamatan di lokasi lain yang berdekatan. Pengujian dependensi spasial dapat dilakukan dengan menggunakan uji Moran's I dengan hipotesis yang diuji yaitu tidak muncul indikasi dependensi spasial $\left(\mathrm{H}_{0}\right)$ [6]. Daerah kritis tolak $H_{0}$ jika $\left|Z_{I}\right|>Z_{\alpha / 2}$ yang artinya bahwa terdapat dependensi spasial antar lokasi dengan $\alpha$ adalah taraf signifikansi.

Heterogenitas spasial atau keragaman yang terdapat di setiap lokasi pengamatan ini dapat disebabkan oleh karakteristik di setiap lokasi pengamatan. Pengujian heterogenitas spasial dapat dilakukan menggunakan uji Bruesch-Pagan dengan hipotesis yang diuji yaitu tidak muncul indikasi heterogenitas spasial $\left(\mathrm{H}_{0}\right)$ [7]. Daerah kritis tolak $H_{0}$ jika $B P>\chi_{(k)}^{2}$ atau jika $p$-value $<\alpha$ yang artinya bahwa terdapat heterogenitas spasial dengan $k$ adalah banyaknya prediktor.

\section{E. Geographically Weighted t Regression $(G W t R)$}

Model Geographically Weighted $t$ Regression adalah pengembangan dari model regresi univariat $t$ dimana setiap parameter mempertimbangkan letak geografis, sehingga setiap titik lokasi geografis mempunyai nilai parameter regresi yang berbeda-beda [8]. Model Geographically Weighted $t$ Regression $(G W t R)$ adalah sebagai berikut:

$$
\begin{aligned}
\tau_{i}\left(\mathrm{u}_{i} \mathrm{v}_{i}\right)= & \exp \left(\beta_{0}\left(\mathrm{u}_{i} \mathrm{v}_{i}\right)+\beta_{1}\left(\mathrm{u}_{i} \mathrm{v}_{i}\right) x_{1 i}+\beta_{2}\left(\mathrm{u}_{i} \mathrm{v}_{i}\right) x_{2 i}+\ldots+\right. \\
& \left.\beta_{k}\left(\mathrm{u}_{i} \mathrm{v}_{i}\right) x_{k i}\right) \\
= & \exp \left(\boldsymbol{x}_{i}^{T} \boldsymbol{\beta}\left(\mathrm{u}_{i} \mathrm{v}_{i}\right)\right) \\
= & e^{\boldsymbol{x}_{i}^{T} \boldsymbol{\beta}\left(\mathrm{u}_{i} \mathrm{v}_{i}\right)}
\end{aligned}
$$

Sehingga fungsi kepadatan probabilitas dari $y_{i}$ adalah

$$
\begin{aligned}
f\left(y_{i} \mid \boldsymbol{\beta}\left(v_{i}, v_{i}\right), \psi\right)= & \frac{\Gamma\left(\frac{e^{\boldsymbol{x}_{\boldsymbol{i}}^{T} \boldsymbol{\beta}\left(v_{i}, v_{i}\right)}+1}{2}\right)}{\left(\pi e^{\boldsymbol{x}_{i}^{T} \boldsymbol{\beta}\left(v_{i}, v_{i}\right)}\right)^{\frac{1}{2}} \Gamma\left(\frac{e^{\boldsymbol{x}_{i}^{T} \boldsymbol{\beta}\left(v_{i}, v_{i}\right)}}{2}\right) \psi^{\frac{1}{2}}} \\
& {\left[1+\frac{y_{i}^{2}}{e^{\boldsymbol{x}_{i}^{T} \boldsymbol{\beta}\left(v_{i}, v_{i}\right)} \psi}\right]^{-\frac{e^{x_{i}^{2} \boldsymbol{\beta}\left(v_{i}, v_{i}\right)}+1}{2}} }
\end{aligned}
$$

Proses penaksiran parameter model $G W t R$ di suatu titik $\left(u_{i}, v_{i}\right)$ membutuhkan adanya pembobot spasial dimana pembobot yang digunakan adalah fungsi kernel gaussian

Fungsi kernel fixed memiliki nilai bandwidth yang sama untuk semua lokasi pengamatan, fungsi pembobot dari fungsi kernel fixed gaussian adalah sebagai berikut [9].

$$
w_{j}\left(u_{i}, v_{i}\right)=\sqrt{\exp \left(-\frac{1}{2}\left(\frac{\left(d_{i j}\right)}{b}\right)^{2}\right)}
$$

dengan $d_{i j}=\sqrt{\left(u_{i}-u_{j}\right)^{2}+\left(v_{i}-v_{j}\right)^{2}}$ adalah jarak eucli-dean antara lokasi $\left(u_{i}, v_{i}\right)$ ke lokasi $\left(u_{j}, v_{j}\right)$ dan $b$ adalah parameter non negatif yang diketahui dan biasanya disebut parameter penghalus (bandwidth). Bandwidth dapat dianalogikan sebagai radius dari suatu lingkaran, sehingga sebuah titik yang berada di dalam radius lingkaran masih dianggap memiliki pengaruh.

Pengujian parsial parameter model GWtR digunakan untuk mengetahui signifikansi pada masing-masing parameter $\boldsymbol{\beta}\left(u_{i}, v_{i}\right)$

Hipotesis :

$H_{0}: \beta_{j}\left(u_{i}, v_{i}\right)=0$

$H_{1}: \beta_{j}\left(u_{i}, v_{i}\right) \neq 0 ; i=1,2, \mathrm{~K}, k ; j=1,2, \mathrm{~K}, k$

Statistik uji :

$$
Z_{h i t}=\frac{\hat{\beta}_{j}\left(u_{i}, v_{i}\right)}{S E\left(\hat{\beta}_{j}\left(u_{i}, v_{i}\right)\right)}
$$

dimana

$S E\left(\hat{\beta}_{j}\left(u_{i}, v_{i}\right)\right)=\sqrt{\operatorname{vâr}\left(\hat{\beta}_{j}\left(u_{i}, v_{i}\right)\right)}, S E\left(\hat{\beta}_{j}\left(u_{i}, v_{i}\right)\right) \quad$ adalah taksiran standart error yang didapatkan dari elemen diagonal ke-j+1 dari matriks varian covarian $\left(\hat{\beta}_{j}\left(u_{i}, v_{i}\right)\right)$. Jika tingkat signifikansi sebesar $\alpha$, maka keputusan tolak $\mathrm{H}_{0}$ jika $\left|Z_{h i t}\right|>Z_{\alpha / 2}$.

\section{F. Pemilihan Model Terbaik}

Pemilihan model terbaik merupakan proses evaluasi dari model untuk mengetahui seberapa besar peluang masingmasing model yang terbentuk sudah sesuai dengan data. AIC (Akaike's Information Criterion) merupakan salah satu kriteria yang digunakan dalam pemilihan model yang terbaik. Jika dua model dibandingkan, maka model dengan nilai AIC yang terkecil merupakan model yang lebih baik Penentuan nilai AIC dilakukan dengan perhitungan sebagai berikut.

$$
A I C=-2 \ln \hat{L}(\hat{\theta})+2 k
$$




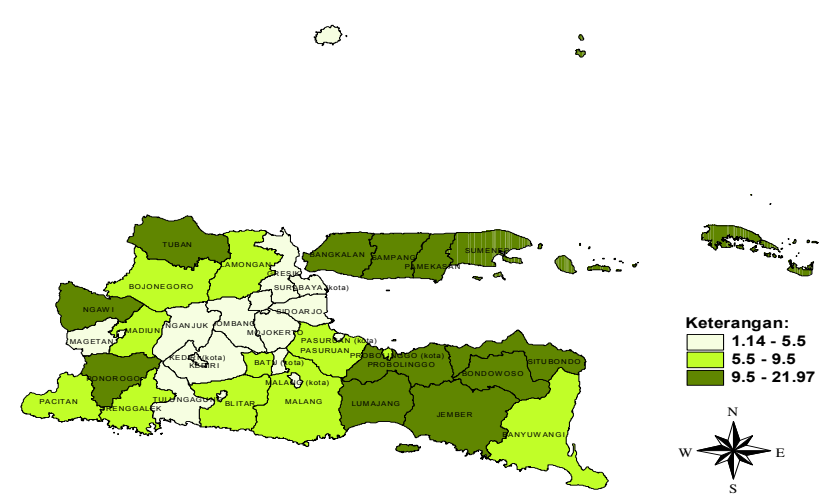

Gambar 1. Persebaran Angka Buta huruf.

\section{G. Angka Buta Huruf (ABH)}

Angka Buta Huruf (ABH) merupakan suatu indikator yang menunjukkan ketertinggalan sekelompok penduduk tertentu dalam mencapai pendidikan. Angka Buta Huruf ini dapat juga digunakan sebagai indikator untuk melihat pencapaian program-program pemerintah dalam usahanya memberantas buta aksara. Tingkat buta huruf rendah atau tingkat melek huruf yang tinggi menunjukkan adanya sebuah sistem pendidikan dasar yang efektif dan atau program keaksaraan yang memungkinkan sebagian besar penduduk untuk memperoleh kemampuan menggunakan kata-kata tertulis dalam kehidupan sehari-hari dan melanjutkan pembelajarannya. Hal yang terpenting adalah meningkatkan kesadaran masyarakat bahwa pendidikan sangat diperlukan bagi setiap individu. Sehingga programprogram pembangunan dalam bidang pendidikan yang dicanangkan pemerintah dapat berhasil sesuai dengan yang tujuan yang diharapkan [10].

\section{METODOLOGI PENELITIAN}

Data yang digunakan dalam penelitian ini merupakan data sekunder yang diperoleh dari Susenas 2015 yang dipublikasikan dalam Statistika Pendidikan Provinsi Jawa Timur 2015 mengenai data Angka Buta Huruf. Data sekunder dalam penelitian ini akan dipakai unit observasi di 38 kabupaten/kota di Provinsi Jawa Timur.

Variabel respon penelitian ini adalah angka buta huruf, sedangkan variabel prediktor yang digunakan adalah angka partisipasi murni tingkat $\mathrm{SD}\left(\mathrm{X}_{1}\right)$, rasio murid-guru $\left(\mathrm{X}_{2}\right)$, rasio murid-sekolah $\left(\mathrm{X}_{3}\right)$, tingkat pengangguran terbuka $\left(\mathrm{X}_{4}\right)$, persentase daerah berstatus kota $\left(\mathrm{X}_{5}\right)$, persentase penduduk miskin $\left(\mathrm{X}_{6}\right)$ dan persentase balita gizi buruk $\left(\mathrm{X}_{7}\right)$

Langkah analisis dalam penelitian ini adalah sebagai berikut.

1. Mendeskripsikan variable angka buta huruf dan faktorfaktor yang mempengaruhi tiap kabupaten/kota di provinsi Jawa Timur dengan peta tematik.

2. Pemeriksaan nilai VIF pada variabel prediktor untuk mendeteksi adanya kasus multikolinearitas.

3. Melakukan pengujian kesesuaian distribusi menggunakan statistik uji Kolmogorov-Smirnov.

4. Memodelkan angka buta huruf di kabupaten/kota seJawa Timur dengan regresi t.

5. Melakukan pengujian efek spasial.

6. Melakukan pemodelan $G W t R$ pada angka buta huruf di kabupaten/kota se-Jawa Timur

7. Membandingkan nilai AIC.

\section{ANALISIS DAN PEMBAHASAN}

\section{A. Deskripsi Variabel Angka Buta Huruf dan Faktor- Faktor yang diduga Mempengaruhi}

Persebaran angka buta huruf dapat dilihat melalui sebuah peta yang disebut peta tematik. Berikut adalah peta untuk persebaran angka buta huruf kabupaten/kota se-Jawa Timur tahun 2015.

Kabupaten/kota yang memiliki angka buta huruf dengan kategori sedang yang digambarkan dengan warna hijau muda realtif lebih banyak dibandingkan dengan kategori tinggi dan rendah. Sedangkan kabupaten/kota yang memiliki angka buta huruf dengan kategori rendah sebanyak 14 kabupaten/kota dan kabupaten/kota yang memiliki angka buta huruf dengan kategori tinggi sebanyak 13 kabupaten/kota. Selain persebaran angka buta huruf juga akan diketahui deskripsi dari angka buta huruf dan faktorfaktor yang mempengaruhinya.

Tabel 1.

Deskripsi Angka Buta Huruf dan Faktor-faktor yang Mempengaruhi

\begin{tabular}{lrr}
\hline \hline Variabel & Mean & Varians \\
\hline Angka Buta Huruf $(Y)$ & 7,51 & 27,79 \\
Angka Partisipasi Murni Tingkat SD $\left(\mathrm{X}_{1}\right)$ & 97,38 & 2,08 \\
Rasio Murid-Guru $\left(\mathrm{X}_{2}\right)$ & 14,99 & 21,87 \\
Rasio Murid-Sekolah $\left(\mathrm{X}_{3}\right)$ & 194,10 & 7996,90 \\
Tingkat Pengangguran Terbuka $\left(\mathrm{X}_{4}\right)$ & 4,36 & 2,99 \\
Persentase Daerah Berstatus Kota $\left(\mathrm{X}_{5}\right)$ & 45,20 & 1055,32 \\
Persentase Penduduk Miskin $\left(\mathrm{X}_{6}\right)$ & 12,16 & 25,34 \\
Persentase Balita Gizi Buruk $\left(\mathrm{X}_{7}\right)$ & 0,22 & 0,05 \\
\hline \hline
\end{tabular}

Berikut adalah deskripsi dari angka buta huruf dan faktorfaktor yang mempenagruhinya dilihat dari nilai mean dan varians. Selain nilai mean dan varians juga akan diketahui kabupaten/kota yang memiliki nilai tertinggi dan terendah untuk angka buta huruf dan faktor-faktor yang mempengaruhinya.

Tabel 2.

Deskripsi Angka Buta Huruf dan Faktor-faktor yang Mempengaruhi(Lanjutan)

\begin{tabular}{ccc}
\hline \hline Variabel & Min & Max \\
\hline Angka Buta Huruf $(\mathrm{Y})$ & Kab. Sidoarjo & Kab. Sampang \\
Angka Partisipasi Murni & Kab. Mojokerto & Kab. Malang \\
Tingkat SD $\left(\mathrm{X}_{1}\right)$ & Kab. Bondowoso \\
Rasio Murid-Guru $\left(\mathrm{X}_{2}\right)$ & Kab. Situbondo & Kota Mojokerto \\
Rasio Murid-Sekolah $\left(\mathrm{X}_{3}\right)$ & Kab. Lamongan & Kota Blitar \\
Tingkat Pengangguran & Kab. Pacitan & Kota Kediri \\
Terbuka $\left(\mathrm{X}_{4}\right)$ & & Kota Kediri \\
& & Kota Blitar \\
Kersentase Daerah Berstatus & Kab. Sampang & Kota Malang \\
Kota $\left(\mathrm{X}_{5}\right)$ & & Kota Pasuruan \\
& & Kota Madiun \\
Persentase Penduduk Miskin & Kota Malang & Kab. Sampang \\
$\left(\mathrm{X}_{6}\right)$ & Kab. Jombang & Kab. Nganjuk \\
$\left(\mathrm{X}_{7}\right)$ & &
\end{tabular}

Setelah mengetahui persebaran dan juga deskripsi dari variabel angka buta huruf dan faktor-faktor yang mempengaruhinya maka dapat dilakukan analisis lebih lanjut.

\section{B. Deteksi Multikolinearitas}

Pendeteksian multikolinearitas menggunakan nilai variance inflation factors (VIF) ditampilkan dalam Tabel 3 sebagai berikut. 
Tabel 3.

Nilai VIF Variabel Prediktor

\begin{tabular}{crc}
\hline \hline Variabel Prediktor & VIF 1 & VIF 2 \\
\hline Angka Partisipasi Murni SD $\left(\mathrm{X}_{1}\right)$ & 1,459 & 1,082 \\
Rasio Murid-Guru $\left(\mathrm{X}_{2}\right)$ & 6,595 & 1,471 \\
Rasio Murid-Sekolah $\left(\mathrm{X}_{3}\right)$ & 15,534 & - \\
Tingkat Pengangguran Terbuka $\left(\mathrm{X}_{4}\right)$ & 1,700 & 1,531 \\
Daerah Berstatus Kota $\left(\mathrm{X}_{5}\right)$ & 13,058 & - \\
Rasio Penduduk Miskin $\left(\mathrm{X}_{6}\right)$ & 3,895 & 1,623 \\
Rasio Balita Gizi Buruk $\left(\mathrm{X}_{7}\right)$ & 1,268 & 1,198 \\
\hline \hline
\end{tabular}

Nilai VIF 1 pada variabel Rasio murid-sekolah $\left(\mathrm{X}_{3}\right)$ dan Tingkat Pengangguran Terbuka $\left(\mathrm{X}_{4}\right)$ lebih dari 10 sehingga melanggar asumsi multikolinieritas. Dikarenakan variabel tersebut melanggar asumsi multikolinieritas maka kedua variabel tersebut dihilangkan.

Nilai VIF 2 adalah nilai VIF dari variabel prediktor setelah menghilangkan variabel Rasio Murid-Sekolah dan variabel Daerah Berstatus Kota. Nilai VIF dari semua variabel prediktor telah kurang dari 10 maka asumsi multikolinieritas terpenuhi. Sehingga variabel yang digunakan adalah Angka Partisipasi Murni SD $\left(\mathrm{X}_{1}\right)$, Rasio murid-guru $\left(\mathrm{X}_{2}\right)$, Tingkat Pengangguran Terbuka $\left(\mathrm{X}_{3}\right)$, Rasio Penduduk Miskin $\left(\mathrm{X}_{4}\right)$ dan Rasio Penduduk Miskin $\left(\mathrm{X}_{5}\right)$. Dikarenakan tidak terdapat kasus multikolinearitas maka dapat dilanjutkan dengan analisis regresi.

\section{Pengujian Distribusi}

Pengujian dilakukan menggunakan pengujian Kolomogorov-Smirnov. Variabel respon angka buta huruf di kabupaten/kota se-Jawa Timur diduga mengikuti distribusi t. Didapatkan nilai $p$-value dari angka buta huruf di kabupaten/kota se-Jawa Timur sebesar 0,6466. Nilai p-value lebih besar dari taraf signifikansi 5\% sehingga diputuskan gagal tolak $\mathrm{H}_{0}$ yang artinya angka buta huruf di kabupaten/kota se-Jawa Timur mengikuti distribusi $t$.

\section{Regresit}

Hasil estimasi parameter model regresi t pada angka buta huruf di kabupaten/kota se-Jawa Timur pada Tabel 4.

Tabel 4.

Estimasi Parameter Model Regresi t

\begin{tabular}{ccrc}
\hline \hline Parameter & Estimasi & \multicolumn{1}{c}{ Std. Error } & Z hitung \\
\hline$\beta_{0}$ & $-31,47615$ & 10,25919985 & $-3,068090^{*}$ \\
$\beta_{1}$ & 0,3265633 & 0,10390786 & $3,142816^{*}$ \\
$\beta_{2}$ & $-0,1039970$ & 0,03681061 & $-2,825192^{*}$ \\
$\beta_{3}$ & $-0,3076414$ & 0,10338152 & $-2,975788^{*}$ \\
$\beta_{4}$ & 0,8059166 & 0,03639313 & $22,144747^{*}$ \\
$\beta_{5}$ & 1,2501142 & 0,73683675 & $1,696596^{*}$ \\
Devians $\left(\mathrm{G}^{2}\right)=41,96502$ & \multicolumn{2}{c}{$\mathrm{R}-\mathrm{sq}=72,26 \%$} \\
\hline \hline
\end{tabular}

Pengujian secara serentak dilakukan dengan menggunakan hipotesis dan statistik uji $G^{2}$. Tabel 3 menunjukkan hasil pengujian parameter secara serentak, didapatkan nilai $G^{2}$ sebesar 41,96502. Nilai $G^{2}$ dibandingkan dengan nilai $\chi_{(5,0.1)}^{2}$ yaitu sebesar 9,236357 didapatkan hasil bahwa nilai $G^{2}$ lebih besar dari 9,236357 sehingga diputuskan tolak $\mathrm{H}_{0}$ yang artinya terdapat minimal satu variabel prediktor yang berpengaruh secara signifikan terhadap angka buta huruf.
Tabel 5.

Variabel yang Signifikan dalam Model GWtR Angka Buta Huruf

\begin{tabular}{cc}
\hline \hline Kabupaten/Kota & $\begin{array}{c}\text { Variabel yang } \\
\text { Berpengaruh } \\
\text { Signifikan }\end{array}$ \\
\hline Ngawi, Gresik, Batu & $\mathrm{X}_{1}, \mathrm{X}_{2}, \mathrm{X}_{3}, \mathrm{X}_{4}, \mathrm{X}_{5}$ \\
\hline Pacitan, Ponorogo, & \\
Trenggalek, Tulungagung, Blitar, Kediri, \\
Malang, Lumajang, Jember, \\
Banyuwangi, Bondowoso, Situbondo, \\
Probolinggo, Pasuruan, Sidoarjo, Mojokerto, \\
Jombang, Nganjuk, Madiun, Magetan, \\
Bojonegoro, Tuban, Lamongan, Bangkalan, \\
Sampang, Pamekasan, Sumenep, Kediri, Blitar, \\
Malang, Probolinggo, Pasuruan, Mojokerto, \\
Madiun, Surabaya.
\end{tabular}

Tabel 3 menunjukkan nilai Zhitung semua variabel prediktor lebih besar dari 1,64 sehingga diputuskan tolak $\mathrm{H}_{0}$ yang artinya variabel angka partisipasi murni SD $\left(\mathrm{X}_{1}\right)$, rasio murid-guru $\left(\mathrm{X}_{2}\right)$, tingkat pengangguran terbuka $\left(\mathrm{X}_{3}\right)$, persentase penduduk miskin $\left(\mathrm{X}_{4}\right)$ dan persentase balita gizi buruk $\left(\mathrm{X}_{5}\right)$ berpengaruh signifikan terhadap angka buta huruf di Kabupaten/Kota se-Jawa Timur. Model regresi $t$ dari angka buta huruf yang dihasilkan adalah sebagai berikut.

$\hat{y}=-31,476+0,3265 X_{1}-0,103997 X_{2}-0,3076 X_{3}+0,8059 X_{4}+1,25 X_{5}$

Jika angka partisipasi murni SD bertambah satu satuan maka angka buta huruf sebesar 0,3265\%. Jika rasio muridguru berkurang satu satuan maka angka buta huruf sebesar $0,10399 \%$. Jika persentase tingkat pengangguran terbuka berkurang satu satuan maka angka buta huruf sebesar $0,3076 \%$. Jika persentase penduduk miskin sebesar bertambah satu satuan maka angka buta hurud sebesar $0,80597 \%$ dan jika persentase balita gizi buruk bertambah satu satuan maka angka buta huruf sebesar $1,25 \%$.

\section{E. Efek Spasial}

Sebelum dilakukan pemodelan menggunakan GWtR, terlebih dahulu dilakukan pengujian aspek spasial, yaitu dependensi spasial dan heterogenitas spasial. Berdasarkan hasil analisis yang dilakukan, didapatkan nilai $p$-value Angka Buta Huruf sebesar 0,3765. Nilai p-value dibandingkan dengan taraf signifikansi 5\%, maka nilai $p$ value lebih besar dari $5 \%$ yang artinya gagal tolak $\mathrm{H}_{0}$. Hal ini dapat disimpulkan bahwa tidak terdapat dependensi spasial pada data Angka Buta Huruf.

Pengujian heterogenitas spasial dilakukan untuk melihat adanya keragaman secara geografis. Uji yang digunakan adalah uji Bruesch-Pagan. Berdasarkan hasil analisis didapatkan nilai statistik Breusch Pagan pada Angka Buta Huruf sebesar 8,938. Pada taraf signifikansi 5\% didapatkan nilai $\chi_{(0,05 ; 5)}^{2}$ sebesar 1,1455 sehingga nilai BP pada Angka Buta Huruf lebih besar dari $\chi_{(0,05 ; 5)}^{2}$ yang artinya tolak $\mathrm{H}_{0}$. Hal ini dapat disimpulkan bahwa terdapat heterogenitas spasial pada data Angka Buta Huruf Kabupaten/Kota SeJawa Timur tahun 2015. Oleh karena itu analisis Angka Buta Huruf dilanjutkan pada pemodelan geographically weighted t regression (GWtR).

\section{F. Geographically Weighted t Regression}

Pemodelan GWtR dilakukan dengan menambahkan pembobot spasial fungsi kernel fixed gaussian. Hasil pengujian parameter secara serentak, didapatkan nilai $G^{2}$ sebesar 77,83637. Nilai $G^{2}$ dibandingkan dengan nilai 
$\chi_{(5,0.1)}^{2}$ yaitu sebesar 9,236357 didapatkan hasil bahwa nilai

$G^{2}$ lebih besar dari 9,236357 sehingga diputuskan tolak $\mathrm{H}_{0}$ yang artinya terdapat minimal satu variabel prediktor yang berpengaruh secara signifikan terhadap angka buta huruf dengan menggunakan metode GWtR. Maka selanjutnya dilakukan pengujian parameter secara parsial yang bertujuan untuk mengetahui variabel prediktor mana yang berpengaruh signifikan terhadap angka buta huruf. Hasil pengujian signifikansi parameter model $G W t R$ pada bulan November ditampilkan dalam Tabel 5.

Tabel 5. menunjukkan bahwa terdapat dua kelompok titik pengamatan. Kelompok pertama adalah variabel angka partisipasi murni tingkat $\mathrm{SD}\left(\mathrm{X}_{1}\right)$, rasio murid-guru $\left(\mathrm{X}_{2}\right)$, tingkat pengangguran terbuka $\left(\mathrm{X}_{3}\right)$, persentase penduduk miskin $\left(\mathrm{X}_{4}\right)$ dan persentase balita gizi buruk $\left(\mathrm{X}_{5}\right)$ berpengaruh signifikan di kabupaten Ngawi, kabupaten Gresik dan kota Batu. Pada kelompok kedua adalah variabel angka partisipasi murni tingkat $\mathrm{SD}\left(\mathrm{X}_{1}\right)$, rasio murid-guru $\left(\mathrm{X}_{2}\right)$, tingkat pengangguran terbuka $\left(\mathrm{X}_{3}\right)$ dan persentase penduduk miskin $\left(\mathrm{X}_{4}\right)$ yang berpengaruh signifikan di semua kabupaten/kota se-Jawa Timur kecuali tiga kabupaten/kota pada kelompok pertama. Persebaran pada peta tematik dapat dilihat pada gambar.

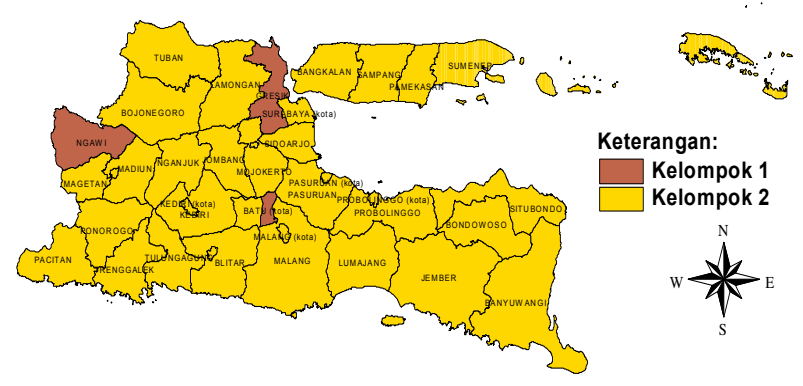

Gambar 2. Pengelompokkan Angka Buta Huruf dengan Metode GWtR.

\section{G. Pemilihan Model Terbaik}

Pemilihan model terbaik berdasarkan nilai AIC pada model regresi t dan $G W t R$ ditampilkan pada Tabel 6 sebagai berikut.
Kriteria nilai AIC adalah, model dikatakan baik ketika memiliki nilai AIC yang kecil. Selain AIC juga dapat dilihat dari nilai $\mathrm{R}^{2}$. Model yang baik memiliki nilai $\mathrm{R}^{2}$ yang besar. Tabel 5 menunjukkan bahwa pemodelan GWtR lebih baik dalam memodelkan angka buta huruf di kabupaten/kota seJawa Timur karena memiliki nilai AIC yang lebih kecil dan nilai $\mathrm{R}^{2}$ yang lebih besar dari pada pemodelan regresi $\mathrm{t}$. Pada variabel angka buta huruf sendiri terdapat heterogenitas spasial sehingga pemodelan $G W t R$ lebih baik dalam memodelkan angka buta huruf di kabupaten/kota seJawa Timur dibandingkan dengan pemodelan regresi t.

\section{KESIMPULAN DAN SARAN}

Hasil pemodelan regresi $t$ menunjukkan bahwa variabel yang berpengaruh signifikan adalah angka partisipasi murni tingkat $\mathrm{SD}$, rasio murid-guru, tingkat pengangguran terbuka, persentase penduduk miskin dan persentase balita gizi buruk. Untuk pemodelan GWtR dengan fungsi pembobot fixed gaussian didapatkan bahwa terdapat dua kelompok titik pengamatan. Kelompok pertama adalah variabel angka partisipasi murni tingkat $\mathrm{SD}$, rasio murid-guru, tingkat pengangguran terbuka, persentase penduduk miskin dan persentase balita gizi buruk berpengaruh signifikan di kabupaten Ngawi, kabupaten Gresik dan kota Batu. Pada kelompok kedua adalah variabel angka partisipasi murni tingkat SD, rasio murid-guru, tingkat pengangguran terbuka dan persentase penduduk miskin yang berpengaruh signifikan di semua kabupaten/kota se-Jawa Timur kecuali tiga kabupaten/kota pada kelompok pertama.

Saran untuk penelitian selanjutnya dapat dilakukan pengujian distribusi yang sesuai dengan variabel respon. Dan pada analisis dengan Geographically Weighted $t$ Regression ditambahkan variabel-variabel baru.

\section{DAFTAR PUSTAKA}

[1] Sistem Pendidikan Nasional, "Pendidikan Bagi Umat Manusia," Surabaya, 2003.

[2] Badan Pusat Statistik, "No Title," 2016. [Online]. Available: www.bps.go.id

[3] Fotheringham, Brunsdon, and Charlton., Geographically Weighted Regression: The Abalysis of Spatially Varying Relationship. Chichester: Wiley and Sons, Ltd, 2002.

[4] D. N. Gujarati, Basic Econometrics, 4th ed. New York: Mc Graw Hill, 2004.

[5] S. Kotz and S. Nadarajah, Multivariate $t$ Distribution and Their Application. United Kingdom: Cambridge University Press, 2004.

[6] J. Lee and D. W. Wong, Statistical Analysis with ArcView GIS. Canada: John Willey \& Sons, Inc, 2001.

[7] L. Anselin, Spatial Econometrics: Methods and Models. Dordrecht: Kluwer Academic Publisher, 1988.

[8] H. Sugiarti, Purhadi, Sutikno, and S. W. Purnami, "Penaksir Parameter untuk Model Geographically Weighted t Regression (GWtR)," KNM XVII, pp. 1391-1396, 2014.

[9] W. S. Cleveland and C. Loader, "Local Regression Models," New York, 1998

[10] Susenas, "Statistika Pendidikan Provinsi Jawa Timur," Surabaya, 2015 